\title{
Hacia una concepción intersemiótica de la traducción artística de Violeta Parra ${ }^{1}$
}

\section{Towards an intersemiotic conception of Violeta Parra's artistic translation}

\author{
Alejandro Escobar Mundaca ${ }^{2}$
}

\begin{abstract}
Resumen
La interrelación de la obra de Violeta Parra (VP) ha tenido menos atención analítica de la que merece, siendo una de los primeros artistas chilenos en pintar sus canciones como lo muestra su pintura Casamiento de negros. De hecho, gran parte de esta actividad artística, de traducir un texto, muestra una amplia y sorprendente relación con la práctica tradicional de la traducción [lingüística]; desde el acto de 'traducir' el 'texto hablado' como llama G. Soublette al Cantos Folklóricos Chilenos, hasta el hecho de tener que traducir al francés canciones y textos durante sus experiencias en Europa. Este artículo propone abordar y analizar esta práctica interdisciplinaria de VP desde algunos estudios literarios y lingüísticos, a partir de la noción Aristotélica de poética, haciendo una breve referencia a una práctica de traducción literaria de Neruda cuya influencia pudo haber tenido resonancia en el trabajo de VP. En tercer lugar se aborda el concepto de 'traducción intersemiótica', desarrollando la principal crítica hecha por Umberto Eco en relación con la distinción entre traductor e intérprete, para finalmente plantear la transposición poética como concepto para comprender y evidenciar esta práctica desarrollada por la creadora chilena.
\end{abstract}

Palabras clave: traducción, poética, traducción intersemiótica, Violeta Parra, Roman Jakobson.

\begin{abstract}
Violeta Parra's interdisciplinary work has had less scholarly attention than it deserves, being one of the first Chilean artists to paint her songs as shown in her painting Casamiento de negros. In fact, much of her artistic activity, of translating a text, shows a broad and surprising relationship with the regular practice of [linguistic] translation; from the act of 'translating' the 'spoken text' as G. Soublette calls Cantos Folklóricos Chilenos, to the practice of translating songs and texts into French during her European performances and exhibitions. This article aims to approach and analyse this interdisciplinary practice of Violeta Parra (VP) following some literary and linguistic studies, from the Aristotelian notion of poetics, a brief reference is made to Neruda's poetical translation whose influence could have had resonance in VP's work. Using the concept of 'intersemiotic translation', the main criticism of Umberto Eco in relation to the distinction between translator and interpreter is discussed to finally posit the concept of poetic transposition to understand and demonstrate this practice widely developed by the Chilean artist.
\end{abstract}

Key words: translation, poetics, intersemiotic translation, Violeta Parra, Roman Jakobson.

\footnotetext{
${ }^{1}$ Trabajo realizado en el marco de la tesis doctoral Translating Poetics: Analysing the Connections Between Violeta Parra's Music, Poetry and Art, Universidad de Sussex, Reino Unido.

${ }^{2}$ Coordinador Orquesta Académica Portuguesa, Lisboa, Portugal. C. elect: alejandromundaca@gmx.com
} 


\section{Introducción}

Tanto los estudios como las antologías de la obra de Violeta Parra han destacado su particularidad interdisciplinaria. Marjorie Agosín e Inés Dölz-Blackbürn (1992) exploraron por primera vez algunas obras plásticas de VP de manera analítica para relacionarla con su obra poética, afirmando que su plástica "forma parte orgánica de su creación poética y de su vida", la cual debe entenderse como un resultado integral en el que "no se puede separar la creación poética de la pictórica, ni de la folclórica" (pp. 115-116), y destacan que "muchas de las imágenes proyectadas en la poesía de VP, y en la elaboración y reelaboración de temas folklóricos, aparecen ejemplificadas en estas pinturas de índole narrativas" (pp. 117-119). Desde esta idea interdisciplinaria se propone desarrollar este trabajo, donde "el texto escrito es como un bordado donde la escritura se convierte en un acto de conjuros y de signos, para luego transformarlo en música y pintura" (Ibid.). En 1993, Miguel Farías incluye la sección, "Las arpilleras son como canciones que se pintan", en su tesis doctoral, en donde advertía que existen otros tipos semióticos de sistemas de interpretación además de la lengua, tradicionalmente privilegiada en los estudios comparados. Desde la perspectiva semiótica, Farías (1993) considera que 'Cuadros de una exposición' de Modesto Musorgsky es un ejemplo de la manera en que un sistema interpretante puede ser otro diferente al lenguaje, abriendo la posibilidad y necesidad de buscar esos otros sistemas interpretantes en la obra visual y musical de VP:

De interés para este estudio global de la obra de Violeta Parra que propongo sería investigar los mecanismos por los cuales se efectúa la transposición de una enunciación verbal a una representación a otros sistemas significantes. Para dar un ejemplo de esta posible línea de estudio, se podrían comparar las diferentes menciones de "árbol", de "pájaro", de "pareja humana", que configuran el léxico de la enunciación verbal de los textos de Violeta Parra, y su traducción en la obra pictórica "El Árbol de la Vida", la cual contiene las figuras de un árbol, dos pájaros posados en una de sus ramas y una pareja humana. (p. 243)

En 2007, Isabel Cruz de Amenábar (F. V. Parra, 2008, pp. 26-33), afirma que las analogías entre la forma visual y musical expresadas por Kandinsky se expresan de forma natural en VP. José Ricardo Morales (F. V. Parra, 2008), por su parte, afirma que "el empleo de los recursos y procedimientos de un arte, llevándolos a otro muy distinto, constituye una de las características más importantes de su extensa labor, otorgándole la unidad necesaria por medio de tales transferencias" (p. 37). Morales también explica la fuerte influencia del arte textil en la poesía de Violeta, tradicionalmente desarrollada por mujeres, que describe como una "tapicería poética' en la que VP literal y poéticamente intenta "tejer el relato":

Porque cuando se dice que un tapiz es una canción pintada, el color se hace voz, mientras que el hilo de la voz cantante queda identificado con la línea de lana. De esta manera, no hay límites entre las artes ni existen barreras que las diferencien; son, tal vez aspectos de una sola o, quizá, no hay una sin todas. Los textos poéticos semejan tejidos; las tapicerías devienen cantares; la escultura es de hilos; la línea es color. (p. 45)

Jorge Montealegre (2011) ofrece más tarde un valioso enfoque interdisciplinario abordando la presencia de diferentes temas como la religiosidad de VP. De manera similar, pudimos conocer más tarde cómo el tema de la 'muerte' se encuentra desarrollado en la poesía, la música y las artes visuales de VP, específicamente, la forma en que la estructura figurativa de la pintura Casamiento de negros [Figura 2] se corresponde semióticamente con la estructura musical de la canción del mismo nombre (Escobar-Mundaca, 2012). En 2013, Lorna Dillon realiza en Inglaterra el primer estudio académico del arte visual de VP donde desarrolla una 
hipótesis sobre el arte activista y sociopolítico presente en la obra visual. Dillon (2013) considera la plástica de VP como "narrativas orales", la cual "presenta una exégesis de ideas centrales de la tradición oral, de hecho, de sus propias canciones, en su arte visual" (p. 227). Esta valiosa investigación se centra en la iconografía y morfología que VP utilizaba para representar la cultura popular y oral, la cultura indígena, la religión, la historia y la política. Sin embargo, la contribución más significativa en términos interdisciplinarios para este ensayo se hace en el capítulo dos, 'Translating Aesthetics', donde Dillon explora la manera en que VP tradujo "sus ideas de un género artístico a otro" (p. 222), incluso a través del concepto de écfrasis. Por ejemplo, Dillon observa que en la pintura

El pájaro y la grabadora [Figura 1] Parra traduce su concepción de la práctica artística en una pintura de paisaje: la silueta de una mujer se fusiona con una escena de colinas y el motivo del pájaro aparece sobre el hombro de la mujer. Aunque los colores en la pintura son claramente modernos, hay un eco con la artesanía tradicional: la forma redondeada de la mujer recuerda las populares figuras de papel maché que se encuentran en la artesanía chilena. ${ }^{3}$ (p. 11)

Figura 1, Violeta Parra, sin fecha, El pájaro y la grabadora, óleo sobre tela, 122 x 148 cm, Colección Nicanor Parra. ${ }^{4}$

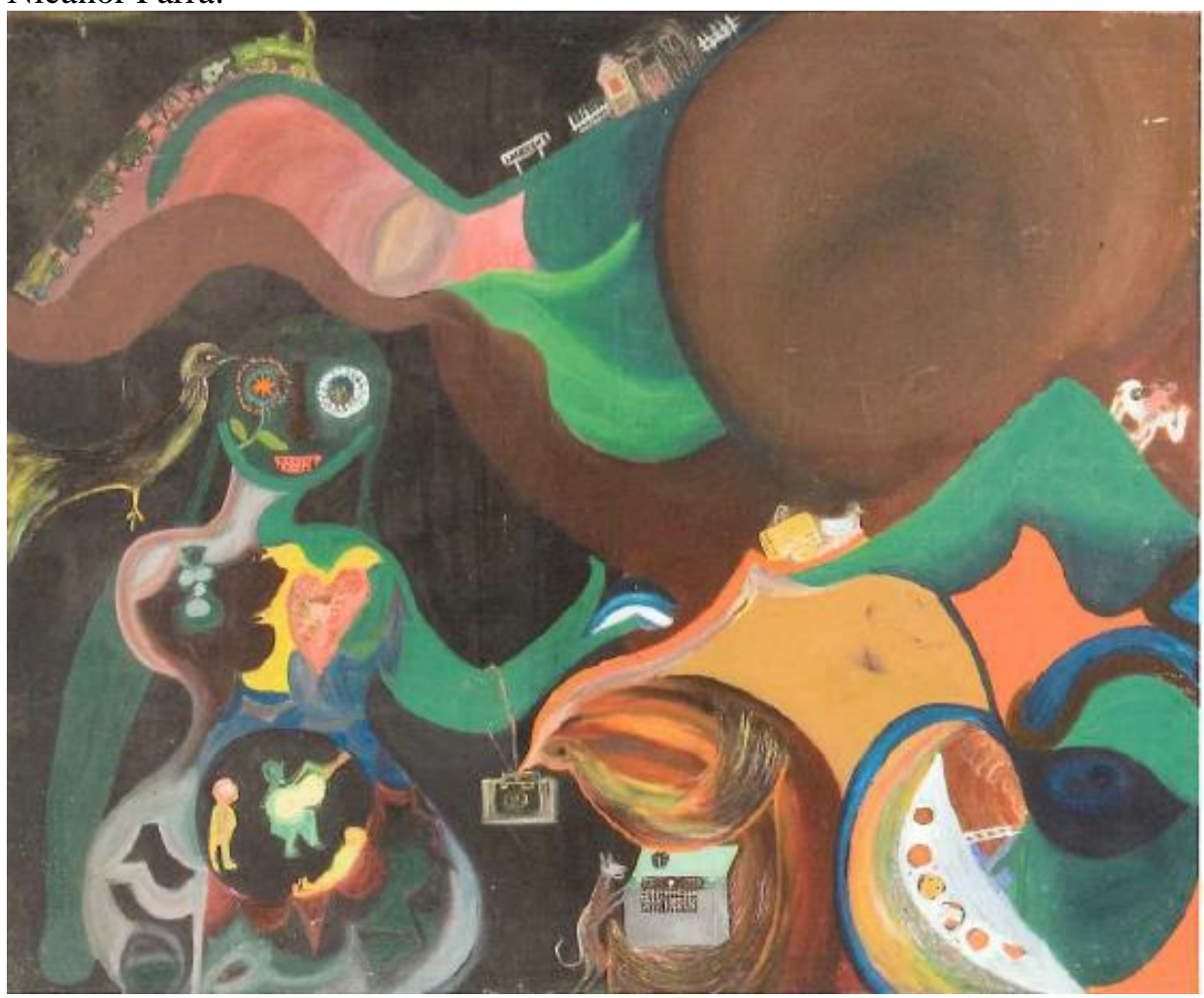

\footnotetext{
${ }^{3}$ Todas las traducciones son del autor de este artículo.

${ }^{4}$ Todas las imágenes provienen de Violeta Parra Obra Visual (F. V. Parra, 2008).
} 
Figura 2, Violeta Parra, sin fecha, Casamiento de negros, óleo sobre tela, 104.5 x $182 \mathrm{~cm}$, colección Nicanor Parra.

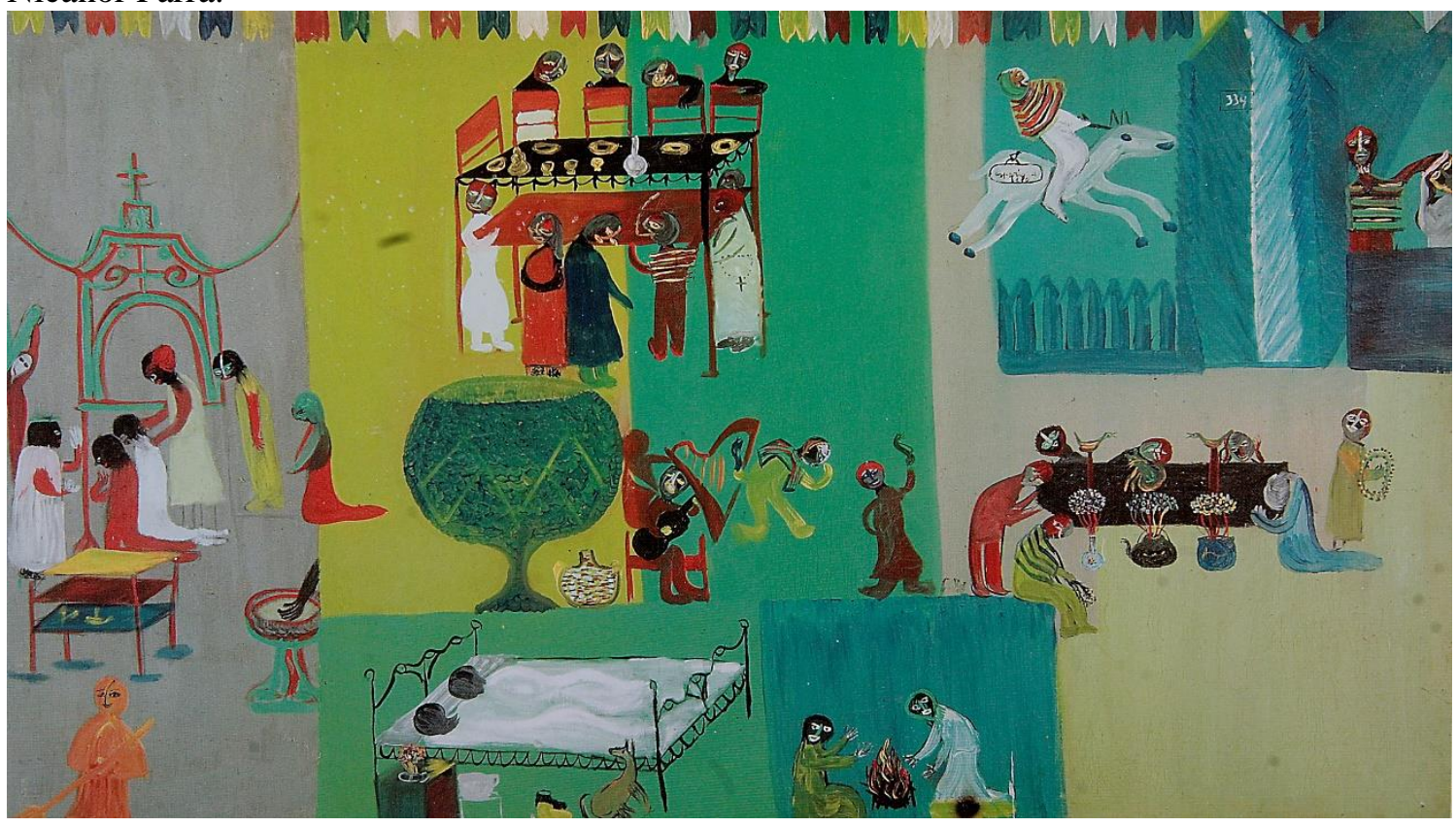

Figura 3, Violeta Parra, 1964, Fiesta en la casa de Violeta, óleo sobre madera prensada, 54 x $98.5 \mathrm{~cm}$, Fundación Museo Violeta Parra.

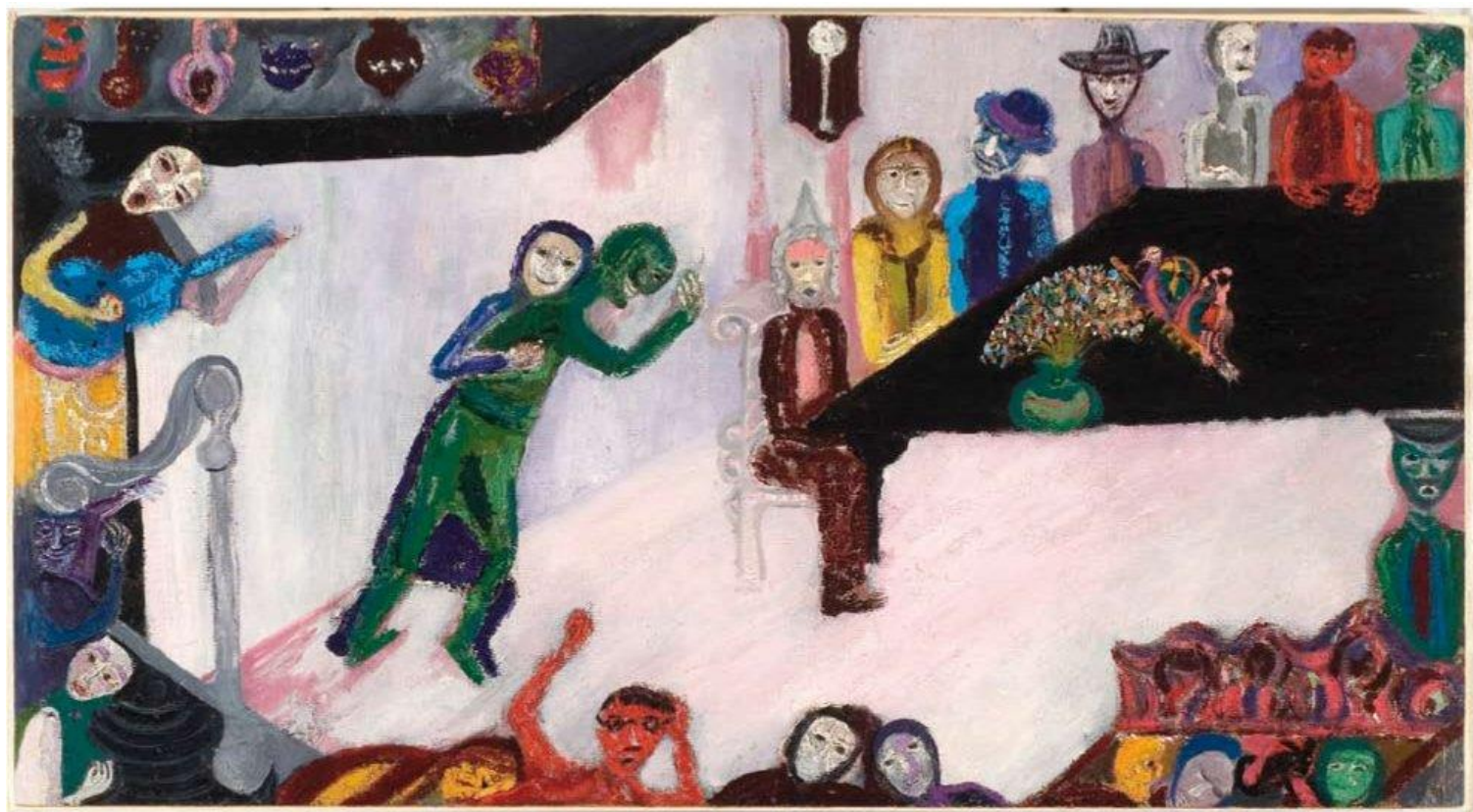


Figura 4, Violeta Parra, Fiesta en casa de los Parra, 87.5 x 124 cm, óleo sobre tela, Fundación Museo Violeta Parra.

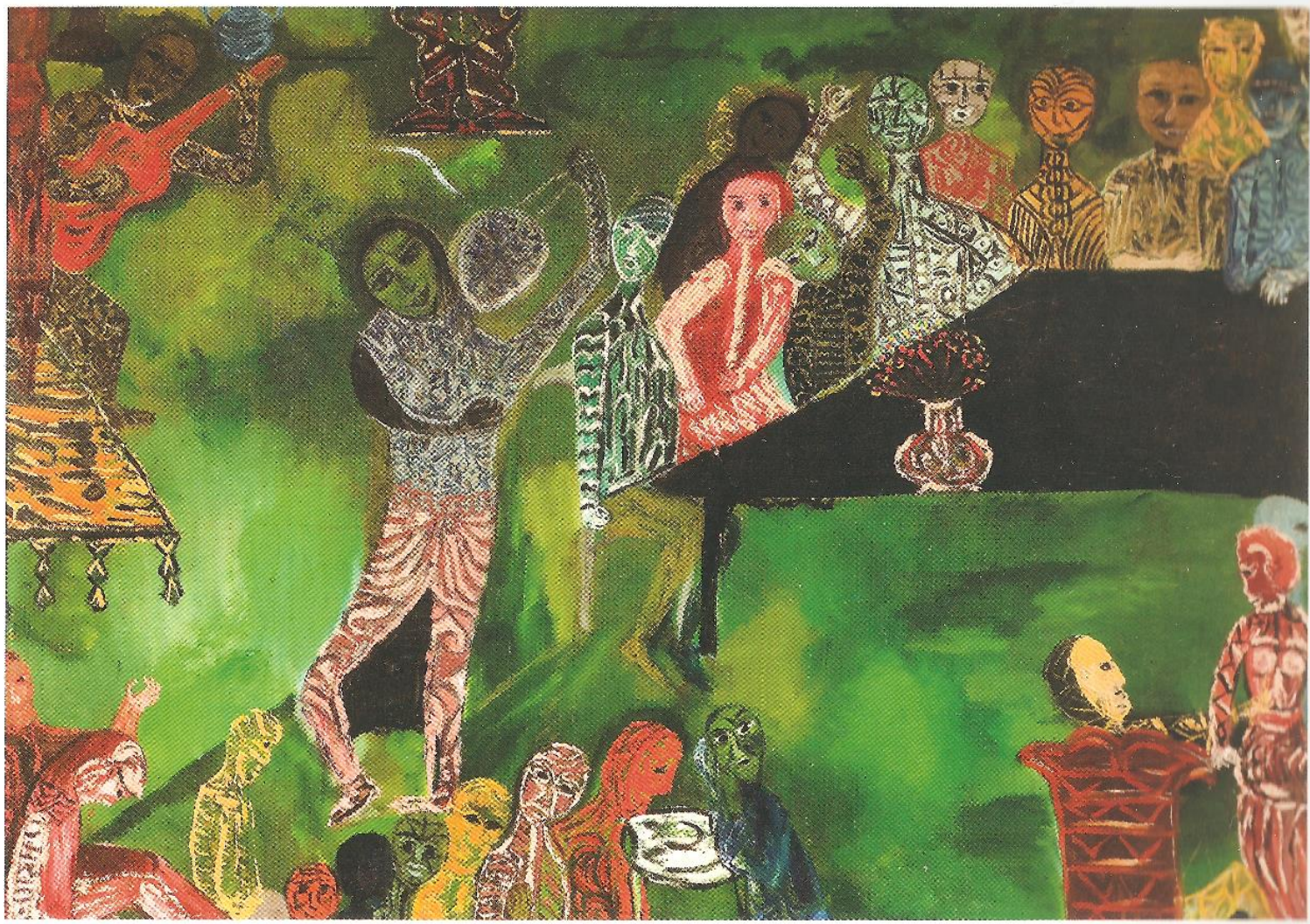

Figura 5, Violeta Parra, 1964-1965, Los Parra, óleo sobre madera prensada, 50 x 80 cm, Fundación Museo Violeta Parra.

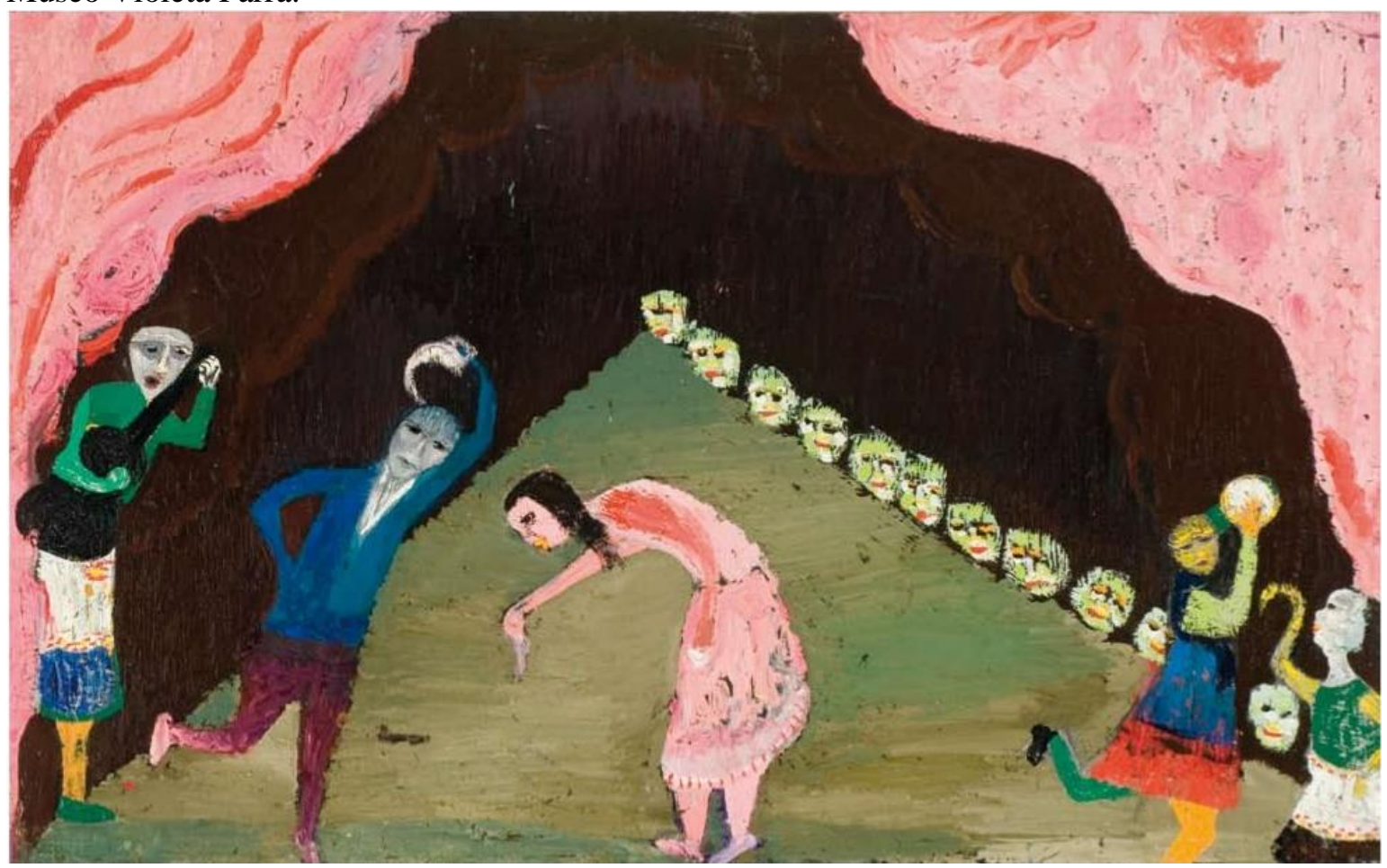

$\underbrace{A}$ 
Así, Dillon detalla que: "Es en la presentación de imágenes de la cultura popular de Parra que la traducción de ideas entre su arte visual y su música es más manifiesta" (p. 226). Esta traducción es expuesta en obras como en Fiesta en la casa de Violeta (F. V. Parra, 2008, p. 101), Fiesta en Casa de los Parra (p. 27), Niños en fiesta (p. 119), y Los Parra (p. 99), donde baile y música son traducidos visualmente, y específicamente usa la cueca para traducirla al lenguaje visual a través de arpillera (p. 72) y papel maché (p. 122).

Aunque el núcleo desde el cual VP concibió su arte interdisciplinario parece provenir de las prácticas rurales chilenas (V. Parra, 1965, 2013), ella comenzó su actividad interdisciplinaria luego de regresar a Chile desde su primer viaje a Europa. Mientras VP admiraba y aprendía de las prácticas tradicionales orales, también se dice que admiraba el arte visual de Pablo Picasso, Marc Chagall y Joan Miró, y la música de Frederic Chopin, Ludwig van Beethoven y los Beatles (Morales, 2003, p. 83; I. Parra, 2011, p. 52). VP vivió en París en su primer viaje, con estancias cortas en Ginebra entre 1954 y 1956, y de 1962 a 1965 durante su segunda estadía (I. Parra, 2011, pp. 226-228). En Francia, pudo incorporarse a un medio multicultural donde convergían los intelectuales y artistas más famosos de todo el mundo, recibiendo comentarios y elogios del reconocido artista chileno Roberto Matta (I. Parra, 2011, p. 182). En este contexto, la obra de VP se define a través de una compleja dualidad en la cual "todo el arte de Violeta Parra, [...] aun cuando la tradición que rescata sea la del folklore, es moderno en un sentido genérico" (Morales, 2003, pp. 65-66), siendo específicamente una [re]creación interdisciplinaria transpuesta artísticamente que está condicionada por la cultura urbana moderna. Así, existen dos ideas principales de consenso: por una parte, la obra de VP debe abordarse en el contexto de las tensiones entre las clases sociales, y por la otra, dentro de las tensiones entre las artes populares y las cultivadas, en el contexto del continuo predominio ideológico de la alta cultura sobre su contraparte subalterna (García Canclini, 1989; Morales, 2003; Pinochet, 2007; Uribe, 2002). Este complejo paradigma artístico, que según J. M. Arguedas, siempre fue visto "como algo excesivamente audaz, como una herejía, alternar ejemplos latinoamericanos con ejemplos europeos" (I. Parra, 2011, p. 57), plantea el desafío metodológico de aproximar conceptos y tradiciones aparentemente diferentes para permitirnos describir los recursos de traducción utilizados por ella (Farias, 1993, p. 84). De esta forma se desarrollará en las siguientes secciones un marco teórico desde tres postulados literarios para delinear la transposición del "lenguaje poético y simbólico" (Brunhammer, 1964, p. 1), específicamente a través de la idea aristotélica de poética, de la traducción nerudiana y de la traducción intersemiótica.

\section{Para una poética de Violeta}

VP declaró que la primera forma de arte que aprendió fue a tocar música en guitarra a la edad de siete años, pero su primera creación fue una canción a la edad de nueve años, y desde entonces comenzó a escribir versos (Vicuña, 1958, pp. 72-73). Más tarde, al comenzar su carrera artística como cantante y compositora, afirmó que el primer género en el que creó fue en el de los versos improvisados conocidos como payas, habiendo escrito doscientos cuarenta y dos versos en cuartetas (Navasal, 1954, p. 18). Por lo tanto, podemos asumir que VP tuvo un dominio importante de la poesía popular desde temprana edad, desde la cual comenzó a "tejer el relato" como un conocimiento artístico para "deletrear con claridez su retrato" (V. Parra, 1998, p. 28).

En una carta de 1961, VP le explica a Favré que su hermano Nicanor le había contado sobre una obra teatral de un dramaturgo inglés, sintiéndose profundamente impresionada al presenciar el espectáculo, describiendo a los personajes y el guion, y señalando que el tema podía aplicarse a cualquier país del mundo. Esto es importantísimo porque demuestra que VP expresamente declara que es posible transportar y hacer la dramaturgia de una obra extranjera:

Nicanor me habló de una pieza de teatro, El cuidador. Lo que me cuenta es formidable. Tres personajes: un enfermo mental, un vagabundo y un hermano del 
enfermo. El vagabundo es como todos los vagabundos, y muestra las consecuencias cuando una persona lo invita a vivir a su casa. Está interpretado muy bien. Creo que, por primera vez, se abre para el teatro en Chile una inmensa puerta. La obra es de Harold Pinter, inglés, pero el tema es de cualquier país. El guion de tu película es muy lindo. Esa idea de araña-mariposa es muy poética. (I. Parra, 2011, p. 121)

Las últimas tres frases de esta cita abren aún más el alcance poético de la obra de VP porque expresan textualmente la interrelación de una idea con lo poético, entendido como generador creativo. Sin embargo, hay varias formas de definir y comprender la poética. Por ejemplo, la definición más simple la describe como el "estudio teórico y práctico de la poesía" (Greene et al., 2012, p. vii) pero específicamente trata el análisis de estructuras verbales (Jakobson, 1987, p. 63). Por estos motivos, el texto literario es objeto de interpretación y descripción con el objetivo de "conocer las leyes generales que presiden el nacimiento de cada obra", y se entiende ampliamente "como la manifestación de una estructura abstracta y general" que "es la expresión de 'algo', y el objetivo de tales estudios es alcanzar este 'algo' a través del código poético" (Newton, 1997, pp. 86-87).

Como sabemos, el término poética fue acuñado por Aristóteles en su libro de Poética [335 a. C.] para establecer las características principales de un "buen poema", donde la épica, el drama y la poesía ditirámbica son considerados como una mimesis, un principio común que comparte con la música, el baile, la pintura y la escultura: "Sin embargo, difieren entre sí en tres aspectos: ya sea en el uso de diferentes medios para la representación, o en la representación de cosas diferentes, o en la representación de ellos de maneras completamente diferentes" (Aristotle, 1922, p. 7). La trama, definida como el "todo" y la "unidad" de las partes, define la calidad y el principio de imitación/representación en la poesía, y se divide en tres categorías. El primer criterio es el "medio" de la imitación poética; por ejemplo, la representación en la pintura se realiza mediante la imitación de colores y formas, mientras que la poesía "se produce por ritmo, lenguaje o "armonía", ya sea de forma individual o combinada" (Ibid.). En la música, la representación o la imitación se produce por el ritmo y la armonía, y en la danza se produce solo por el ritmo imitando "carácter, emoción y acción, por movimiento rítmico"; y, finalmente, la poesía lírica que "imita solo por medio del lenguaje, y que en prosa o en verso [...] puede combinar diferentes métricas" (pp. 7-9). A pesar de que estas definiciones aristotélicas tienen su contexto específico sobre la tragedia como género teatral y dramático, resulta fundamental conocer la esencia interdisciplinaria de la poética.

Desde la perspectiva específica sobre nuestra autora, también encontramos esta noción poética como caracterización interdisciplinaria. Por ejemplo, la definición de Lucy Oporto (2013) de la poética de VP como "la cosmovisión de la artista, que surge del análisis de sus procedimientos estéticos y los procesos de su trabajo" (p. 145). Esta definición resulta pionera en el sentido de que no solo es el primer análisis detallado en donde podemos identificar esos procedimientos estéticos, sino que además se demuestran las "preceptivas de un plan creativo específico, sus mecanismos, procedimientos y resolución de problemas técnicos" como noción estética de poética referenciada por Oporto (Ibid.).

\section{La traducción nerudiana}

Como hemos visto en el caso de la influencia de Nicanor Parra sobre su hermana con la obra $E l$ cuidador, también se advierten influencias insoslayables de la práctica de traducción en el contexto de la propia VP que conviene incorporar en esta discusión. Es el caso de su amigo Pablo Neruda quien tradujo en 1964 Romeo y Julieta de William Shakespeare, evitando una traducción literal, haciendo más bien una recreación del texto en una versión libre más cercana a la paráfrasis, acomodando "el lenguaje, haciéndolo más directo, más ágil, menos reiterativo. Y buscó ese objetivo suprimiendo, abreviando, resumiendo, concentrando, entresacando ejemplos, 
descripciones, imágenes y fragmentos completos" (Ulloa, 1997, p. 87). Es más, es posible advertir grandes diferencias de traducción incluso dentro del mismo lenguaje, por ejemplo, cuando se comparan las versiones de España y Chile, de la misma forma que el inglés británico del estadounidense (p. 88). Para Neruda, existe una diferencia ideológica entre el idioma español de América Latina y el "original" de España, porque este último está impregnado de la poética de Luis de Góngora y se convirtió en "dorado" gracias a la "elegancia cortesana" de Francisco de Quevedo; mientras tanto, la poesía latinoamericana "piedra polvorienta, de lava triturada, de arcilla con sangre. [porque] No sabemos tallar el cristal", criticando a aquellos poetas que conservaban el español ibérico y no adaptaban las características locales porque "Una sola gota de vino de Martín Fierro o de la miel turbia de Gabriela Mistral los deja en su sitio: muy paraditos en el salón como jarrones con flores de otra parte" (Neruda, 2011, p. 118).

Sin embargo, es muy probable que VP haya sido muy influenciada por otro texto de Neruda en donde el autor cristaliza no sólo una posición ideológica e histórica americanista, sino que además sentaría un antecedente importante sobre la interrelación visual y textual latinoamericana. En Neruda's Ekphrastic Experience, Hugo Méndez-Ramírez ofrece un estudio detallado de la forma en que el Canto General de Neruda y el arte mural mexicano parecen interrelacionarse. Junto con proporcionar una discusión teórica de la relación entre la representación verbal y visual, Méndez-Ramírez afirma que la palabra écfrasis, "proviene del verbo griego ekphraissien, que significa 'hablar' o 'informar en detalle'. [pero que] En la retórica helenística, su significado era amplio y general [...] para referirse a cualquier descripción verbal de cualquier tipo, ya sea en arte o retórica" (p. 32). De hecho, La primera edición de Canto general se publicó en privado en México en 1950, con dibujos de los muralistas Diego Rivera y David Alfaro Siqueiros (Neruda, 1993, p. 1). De esta forma, y según Méndez-Ramírez (1999), Neruda pudo proporcionar con su Canto general la articulación lingüístico-poética de la que carecían los mensajes ideológicos del muralismo, ejemplificado en el mural Historia de México a través de los siglos de Diego Rivera con el que comparte

...su marco narrativo esencial, comenzando antes de la conquista y terminando en el presente. Las versiones ecfrásticas de Neruda fueron más bien conceptuales que reales. [...] La marca del artista mexicano es evidente en ciertos rasgos de la poesía de Neruda: idealización de las civilizaciones precolombinas, una visión panorámica y sincrónica de la historia, la estructura dialéctica y binaria del Canto general, el concepto de "poeta del pueblo" o el artista como artesano, y la inserción del artista en su propio objeto de arte como un medio de comunión con las masas, el tono propagandístico que a veces parece nublar la perspectiva del poeta, el estilo vanguardista y, finalmente, la naturaleza enciclopédica del volumen. (p. 204)

Prueba de una posible influencia de esta perspectiva ecfrástica nerudiana en VP es establecida en el capítulo 'I Don't Play the Guitar for Applause: Turning the World Upside Down' (Escobar-Mundaca, 2018) donde se detallan los recursos ecfrásticos transportados en la musicalización del poema 'El pueblo', que es parte de Canto general, específicamente a través de la polifonía bajtiana y el 'Mundo al revés' como recursos de inversión.

\section{La traducción intersemiótica}

En sus viajes a Europa, VP se vio enfrentada ante el hecho de tener que traducir y transmitir estos simbolismos locales, y su idioma, para ser entendidos en la URSS, Polonia, Francia, el Reino Unido, Finlandia, Alemania, cada uno de ellos con su propio idioma y cultura. Un ejemplo revelador es la grabación en vivo de su concierto en Ginebra, en donde ella debe recurrir muchas veces a la ayuda de Gilbert Favré para expresarse en francés (V. Parra, 1999). De hecho, en 
1962, VP envió una carta desde esa ciudad en la que hace referencia a este problema usando una metáfora para traducirlo:

Un año y ocho meses que salí al mundo a servir mi tacita de té entre las familias que beben por los ojos y los sentidos. No me entienden la palabra, pero sus rostros se ponen brillantes, y tartamudean de emoción cuando quieren tender ese hilito misterioso entre su sangre y la mía, que se llama amor. Si vieras, Adriana, cómo brillan las arruguitas de los viejos y cómo se aclaran las nubes de sus ojos cuando les entrego mi alma en una cueca o en un cuadro. (I. Parra, 2011, p. 139)

En este sentido, la experiencia artística de VP para comunicar su arte en otro(s) idioma(s) nos remite necesariamente a los estudios literarios para conocer los principales elementos a considerar para este estudio, como por ejemplo cuando esta práctica sugiere un uso variado de símbolos, metáforas y analogías en la búsqueda de significado (Benjamin, 2004, p. 255). Los estudios lingüísticos ofrecen conceptos indispensables para fundamentar un marco teórico sobre la "traducción artística" de VP. De hecho, los estudios de traducción abarcan una amplia variedad de enfoques.

Los estudios lingüísticos ofrecen conceptos indispensables para fundamentar un marco teórico sobre la "traducción artística" de VP. De hecho, los estudios de traducción abarcan una amplia variedad de enfoques. Por ejemplo, Charles Peirce, considerado el padre de la semiótica, afirmó que un "significado" es la "traducción de un signo a otro sistema de signos" (Peirce, 1933, p. 127), y la "interpretación es simplemente otra palabra para la traducción" (Peirce, 1998, p. 388). Aunque las ideas de traducción de Peirce se basan en una tradición específica, sus teorías y definiciones han servido como punto de partida para la lingüística, la semiótica, los estudios de traducción y un vasto cuerpo académico. Por ejemplo, in 1959, el influyente lingüista Roman Jakobson (1987) afirmó que "el significado de cualquier signo lingüístico es su traducción a otro signo alternativo" (p. 429), proporcionando tres amplias categorías de interpretación de un signo verbal. Una traducción (reescrita) dentro del mismo idioma que él llamó 'traducción intralingüística', equivalente a una reformulación en la misma lengua como la paráfrasis; un segundo tipo de traducción (normal) a otro idioma que llamó 'traducción interlingüística por ejemplo la traducción de Neruda antes mencionada; y una tercera traducción que salía del ámbito semiótico lingüístico que llamó 'Transposición intersemiótica' a otro sistema no verbal de símbolos. De hecho, utiliza además la palabra transmutación como sinónimo para resaltar la idea de una transformación semiótica (Ibid.). Esta transposición intersemiótica de Jakobson describe la transferencia de un arte verbal a la música, la danza, el cine o la pintura, aunque no desarrolla detalladamente esta nueva posibilidad de transferencia. Por otro lado Greimas hablaba de transposición como transformación intertextual del lenguaje en la "sustancia del sentido" en su diccionario razonado del lenguaje, y Eco (1979, p. 71) considera la traducción intersemiótica como fundamento de la comunicación cultural. Para el lingüista danés Louis Hjelmslev el lenguaje normal, así como cualquier sistema semiótico, está constituido desde una amalgama conceptual dividida en un plano expresión y otro plano de contenido, cada uno compuesto de un plano de substancia y otro plano de forma (citado en Eco 2004, p. 21).

En su libro ¿Mouse or Rat? Translation as a Negotiation, Umberto Eco (2004) reconoce que uno de los problemas de la traducción es efectivamente "como representar lo que uno ve en palabras", detallando las 'problemáticas' de la traducción intersemiótica (p. 104). A través del efecto retórico de la hipotiposis, Eco intenta contextualizar el desafío de representar escenas visuales en palabras, argumentando que se basa en la écfrasis para garantizar que la traducción realmente recrea la "imagen" originalmente escrita con palabras, estando muy relacionado a la intertextualidad entendida como una referencia textual en diálogo con otro texto. El traductor debe ser un interpretante, por lo tanto, la transferencia debe mantener la sustancia, o lo que sea 
que esté expresando, representado por un signo lingüístico. Porque, según Eco, "El verdadero problema es desarrollar la capacidad de ver el mundo como el poeta lo vio", concluyendo que "la traducción es una cuestión de negociación entre el traductor, el lector y el autor original. [...] [Porque] es nuestro compromiso para aislar lo que es para nosotros el sentido profundo de un texto, y es la buena voluntad lo que nos impulsa a negociar la mejor solución para cada línea" (p.192). De esta manera, a partir de las categorías de traducción de Jakobson, Eco critica la ambigüedad de Jakobson sobre la idea de que la interpretación es una forma de traducción, afirmando que la traducción tripartita de Jakobson sería una 'interpretación' más que traducción misma (p. 123). Eco reafirma que la 'traducción intersemiótica' es "la transformación de una novela en una película, o de una pintura en un poema, etc.” (pp. 1-6), transmitiendo las mismas cosas que el original, por ejemplo, cuando la película Fantasía (1940) de Walt Disney tradujo en imágenes animadas la música de Bach, Beethoven, entre otros (Ibid.), pero también puede considerarse adaptación. Eco también proporciona una definición interdisciplinaria para la "traducción intralingüística" de Jakobson como una forma de "reformulación" en otros sistemas semióticos. En música, dice Eco, se llama transcripción porque "una pieza musical se reescribe en una clave diferente, o se cambia del [...] modo dorio al frigio" (p. 131). Pero Eco (2004) expande esta idea explicando que cuando existe una transcripción de un instrumento a otro estaríamos hablando de una reformulación de la substancia. Por ejemplo, con una suite de Bach para violonchelo solo transcrita para flauta, Eco explica dos efectos de la transcripción. La primera es que la línea melódica se 'transporta' sin variaciones, pero los 'acordes' del acompañamiento deben 'reformularse' en un arpegio porque la flauta no puede tocar más de una nota a la vez, de modo que pueda (re)crear la impresión sonora de tocar la línea melódica al mismo tiempo que los acordes como lo es en su versión original. Y la segunda es que la transcripción cambia el timbre de un instrumento a otro, lo que significa que la "sustancia", tanto el contenido armónico como el melódico, también cambia para el oyente: "cuando se traduce poesía uno debería reproducir lo más posible el efecto que hace el sonido del texto original, a pesar de que en el cambio de idioma son inevitables muchas variaciones" (p. 137). Nicanor hizo una analogía similar cuando habló sobre su experiencia de traductor de Shakespeare al español: "Lear está escrito en un instrumento [musical] que es el idioma inglés, por lo tanto, me gustaría ser el transcriptor de esta composición a otro instrumento que es el idioma español" (Ulloa, 1997).

Esta idea es compartida por David Bellos (2011) quien aborda los diferentes problemas y desafíos a los que se debe hacer frente para hacer que un texto suene más idiomático y natural en un idioma extranjero (p. 46). En el caso de VP, esto significaba que tenía que superar el hecho de que no podía usar algunos localismos porque los países europeos no sabían lo suficiente sobre los localismos chilenos. Sin embargo, esto también puede haber jugado un papel positivo porque al ser desconocidos estos localismos podrían ser percibidos como un exótico "otro". VP enfrentó un desafío identificado por Bellos, quien pregunta: “¿cómo debería representarse entonces mejor lo foráneo de lo extranjero en el idioma receptor?" (p. 42), y respondiendo que la mejor alternativa de traducción de lo foráneo que mantiene los valores locales es justamente dejando aquellas partes en su forma original, al igual que Eco (2004, p. 89). Para Bellos, "la práctica de la traducción se basa en dos condiciones [humanas y bipartitas]" porque "hablamos lenguas diferentes y vemos el mundo de formas profundamente influenciadas por las características particulares de la lengua que hablamos", pero al mismo tiempo "todos somos iguales; podemos compartir los mismos tipos de sentimientos, información, entendimientos, etc.” (p. 338). Así, más que la equivalencia mecánica y fija entre palabras, la traducción está fuertemente influenciada por la interpretación en donde se integran más que simplemente palabras.

Para Eco (2004), la clave de la problemática de la traducción intersemiótica estaría dada más bien por la interpretación como medio de reformulación y adaptación, cuya finalidad está determinada por el 'horizonte' de convenciones [literarias] que influencian las elecciones del 
traductor (p. 143). Por ejemplo, Eco explica que es muy difícil traducir en palabras lo que Beethoven expresa musicalmente en su Quinta Sinfonía, así como 'traducir' en música la Critica de la razón pura, pero si es posible hablar de adaptación o transmutación cuando Debussy transpone el poema L'après-midi d'un faune de Stéphane Mallarmé en su 'Prélude à l'après-midi d'un faune' debido a la presencia de sistemas semióticos con un significado y una sustancia de expresión diferentes (pp. 157-159). Esto hace implícito la idea de que, a pesar de la existencia de similitudes entre diferentes sistemas semióticos, cada obra o sistema semiótico es autónomo y tiene su propia coherencia interna, y su potencial intersemiótico estará condicionado por la capacidad de adaptación de la substancia de expresión (p. 144). Pero esto además abre la opción de una indeterminación metafórica cuando se usa la interpretación como sinónimo de traducción (p. 157). Para Siglind Bruhn (2001), este sería un caso similar cuando se analiza 'Cuadros de una exposición' de Musorgsky, identificándola como una adaptación o representación ecfrástica libre sobre su experiencia temática de la exhibición más que una traducción o adaptación exacta de cada obra plástica en cada una de las partes de la obra musical (p. 555). Las habilidades del intérprete que transfiere significados y substancias de diferentes sistemas semióticos deben encontrar las mejores soluciones para reproducir a través de configuraciones nuevas y enriquecidas.

Así, el éxito de la interpretación se traduce en la eliminación, expansión y condensación de los elementos que dan substancia y significado. En música, se utiliza igualmente la palabra intérprete para describir la práctica de tocar/cantar música, lo que conlleva decisiones similares a la enfrentada por el intérprete traductor, a pesar de que la música de tradición escrita tiene parámetros más o menos establecidos. Podríamos identificar así analogías entre la práctica lingüística y musical del acto de traducir e interpretar signos desde y hacia otros sistemas significantes. Así como la idea poética aristotélica, la efectividad de la interpretación de un signo a otro puede ser evaluada no desde su equivalencia exacta, sino que desde la capacidad de incorporar aquel conjunto de significados de la manera más directa y simple. Al igual que en 'Cuadros de una exposición', Casamiento de negros [Figura 2] no realiza una traducción exacta desde el otro sistema semiótico, sino que hace más bien una transposición estructurada por la coherencia poética y musical de la canción original para la efectividad de la equivalencia semiótica. Por otro lado, podríamos identificar en la pintura El pájaro y la grabadora [Figura 1] una interpretación plástica libre de la 'Décima II' en donde VP narra poéticamente cómo va “'desentierrando' el folklore", y que es posteriormente cantada por la propia autora (V. Parra, 1976, pista 2). No hay elementos para sostener, por ejemplo, desde el estructuralismo jakobsoniano, que esta décima transfiera estructuras de manera intersemiótica desde o hacia la pintura en cuestión, como si sucede con la pintura Casamiento de negros.

\section{Extractos 'Décima II'}

Válgame Dios, Nicanor, si tengo tanto trabajo, que ando de arriba p'abajo desentierrando folklor. No sabís cuánto dolor, miseria y padecimiento me dan los versos qu'encuentro [...] Igual que jardín de flores se ven los campos sembra'os de versos tan delica'os que son perfeutos primores. Ellos cantan los dolores, llenos de fe y esperanzas; algotros piden mudanzas de nuestros amargos males; fatal entre los fatales voy siguiendo estas andanzas. (V. Parra, 1998, p. 25) 


\title{
La transposición poética de Violeta Parra
}

El desafío metodológico de analizar las transferencias nos hace considerar y contrastar la teoría a partir de la traducción intersemiótica desde el carácter autodidacta anclado en la oralidad del arte de VP. Como José Morales sugiere (F. V. Parra, 2008, p. 45), los versos de la 'Décima III' contienen los conceptos claves que este artículo propone desarrollar porque en ella encontramos expresada de manera literal e inequívoca sus fundamentos para una lectura intersemiótica. Como sabemos, las normas establecen que se deletrea el nombre con palabras/sílabas, se toca música con sonidos, y pinta/borda una imagen con figuras/colores. Pero VP revela en esos versos que recurre a elementos visuales para "deletrear" verbalmente su imagen, práctica tradicionalmente conocida como écfrasis. Además, cuando ella expresa que va a "transportar la guitarra" podemos definirlo como una metáfora desde la cual se proyectan múltiples posibilidades, como por ejemplo transportar intersemioticamente hacia su lenguaje plástico y poético en donde es posible reconocer reinterpretaciones y adaptaciones donde substancia y materia son creativamente transpuestos. De la misma manera, VP transportará su propia substancia poética ["el canto de todos que es mi propio canto"] y toda la referencia/intertextualidad de la tradición rural como el 'Canto a lo poeta' para tejer intersemioticamente su relato/interpretación visual y musical como se expondrá a continuación.

\author{
Extracto de la 'Décima III' \\ Primero, pido licencia \\ pa' trasportar la guitarra; \\ después, digo que fue Parra \\ quien me donó l'existencia. \\ Si me falta l'elocuencia \\ para tejer el relato, \\ me pongo a pensar un rato \\ afirmando el 'tuntuneo', \\ a ver si así deletreo \\ con claridez mi retrato. \\ (V. Parra, 1998, p. 28)
}

Aunque no existe certeza, se piensa que VP escribió sus famosas Décimas entre 1958 y 1959 (Morales, 2003, p. 54), así como también las menos conocidas centésimas. Para Paula Miranda (2001, p. 17), VP recrea y reinventa la forma tradicional de la autobiografía popular, utilizando la intertextualidad y el género literario referencial para retratarse autobiográficamente sin dejar de lado características de la ficción para relacionarse con la historia y sociedad en que suceden a través de un discurso: “...entendidos como flujos sémicos, antes de su concreción textual: dichos y refranes, "formas" del canto lo "pueta", oraciones, crítica social, discursos del exilio, del viaje, de los orígenes, del paraíso terrenal, de la maternidad, periodísticos, etc. (Miranda, 2001, p. 19). Estas son las diferentes voces y tradiciones discursivas que integran el horizonte de convenciones desde el cual VP puede "deletrear con claridez" su retrato, y también transportar la tradición del 'Canto a lo Poeta'. Las Décimas (V. Parra, 1976) no son solo 'escritura' de la tradición oral, sino que también poesía cantada con guitarra, situándose, primero en la tradición latinoamericana de la poesía crítica del 'canto a lo humano' (Escobar-Mundaca, 2019), y como extensión en la gran tradición de los juglares y trovadores medievales del sur europeo (Agosín \& Dölz-Blackburn, 1992; Aubrey, 2000). Pero esta práctica que la sitúa en esa grande tradición tiene su consagración cuando ella misma traduce ese 'texto hablado', para citar a Soublette (V. Parra, 2013, p. 10), que es la poesía cantada que ella encontró en las zonas 
rurales de Chile. Para Soublette la investigación de estos cantos hechos por VP fue mucho más que la entonces etnografía practicada en Chile. Cuando VP escribe su investigación no trató solamente de traducir 'fielmente' lo que le transmitieron las personas, sino que además tuvo que

...reconstruir los textos de las canciones. En efecto, dada la antigüedad de la mayoría de los cantos folklóricos y la paulatina pérdida de las tradiciones populares por el desarrollo de la vida urbana, muchas melodías y muchos textos se hallan incompletos, o lo que es más frecuente, mezclados con fragmentos de otros cantos. (V. Parra, 1959, p. 5)

Al leer Cantos Folklóricos Chilenos, se evidencia el trabajo de intérprete realizado, en donde además conocemos el estilo de vida de los cantores, sus modismos, frases y formas de hablar, costumbres, vestimenta, etc. Sin embargo, varios de estos cantos fueron paralelamente interpretados en sus primeros álbumes (V. Parra, 1957, 1958), por ejemplo, en el álbum La Cueca..., VP afirmaba que era tocada ampliamente por mujeres, destacando las 'cuecas largas' (pista 1). Soublette, por su parte, considera que los textos de la cueca tienen un delicado ingenio y humor, al igual que la poesía y pintura medievales europeas, detallando una característica importante de la cueca: la guitarra traspuesta, ampliamente utilizada por cantoras, quienes mostraban una sorprendente habilidad guitarrística y conocimiento de muchos tipos de afinaciones y acompañamiento para cantar. Podemos reconocer la referencia textual, así como la materia y sustancia de transposición en la primera frase con la que comienza el siguiente párrafo, haciendo eco de lo que ella dice poéticamente en la "Décima III" acerca de "transportar la guitarra" y "tejer el relato":

En esta afinación las cantoras campesinas van llevando la melodía de todo lo que cantan, forma de acompañamiento que ellas llaman "haciendo hablar la guitarra". [...] Se practican en esta afinación dos formas de acompañamiento. Uno, es el modo normal de pulsar las cuerdas con todos los dedos y otro que toma el nombre de "por trasporte" y que consiste en hacer un puente con los dedos extendidos, que se traslada sobre el encordado, transportando constantemente el acorde de la afinación, fluctuando entre la tónica, la dominante y la subdominante. Algunas cantoras suelen alternar estas dos formas de ejecución, lo cual da motivo para un elegante y curioso juego en la mano. En la afinación por segunda alta, los cantores tocan la famosa cueca valseada, la mayoría de las veces sin canto, y cuyo punteo se asemeja al acompañamiento de cueca en arpa. (V. Parra, 1959, p. 7)

Estas cantantes hacen hablar la guitarra a través de la guitarra traspuesta una manera particular de tocar la guitarra por medio de "posiciones fijas" de la mano izquierda en busca de la economía de movimiento y cantando con voz gutural y con "glissandos". Estas mismas características fueron interpretadas y transpuestas por VP en 'Tres Cuecas Punteadas' y 'Tres Polkas Antiguas', reformulando la música de salón sin letra; práctica habitual de la música de tradición escrita:

En algunos velorios se interpretan cuecas para animar a los presentes. Estas cuecas se bailan sin pañuelo, sin zapateo y sin canto, y sirven para evitar que las visitas se duerman. Violeta Parra realiza tres melodías chilenas, imitando en la primera al guitarrón, en la segunda al arpa y en la tercera a la "cueca apianada", de origen pueblerino. (V. Parra, 1957) 
De esta manera VP iba a reunir todo este conocimiento derivado de la práctica musical rural para transponerlo creativamente primero en la música, con canciones y música instrumental, y posteriormente de forma casi simultánea en su poesía y obra plástica. Prueba de ello son las posturas de las cabezas inclinadas de las figuras de guitarristas en pinturas como Velorio de Angelito [Figura 5], Fiesta en la casa de Violeta [Figura 3], La guitarrera [Figura 7derecha] y las arpilleras Hombre con guitarra, Thiago de Mello y - el bordado sobre tela sintética - El circo. Existen sistemas significantes de equivalencia en la plástica de VP que nos permiten identificar qué música está pintada, por ejemplo, las figuras que aparecen 'bailando' separadas y con pañuelos en las manos podemos interpretar que la música es la cueca [Figuras 2, 3 y 7 -izquierda], mientras que en aquellas obras en las que aparecen tomados de las manos probablemente están bailando formas como el vals [Figuras 3 y 4 ].

Figura 6, Violeta Parra, 1964, Velorio de angelito, óleo sobre tela, 27 x 41 cm, Fundación Museo Violeta Parra

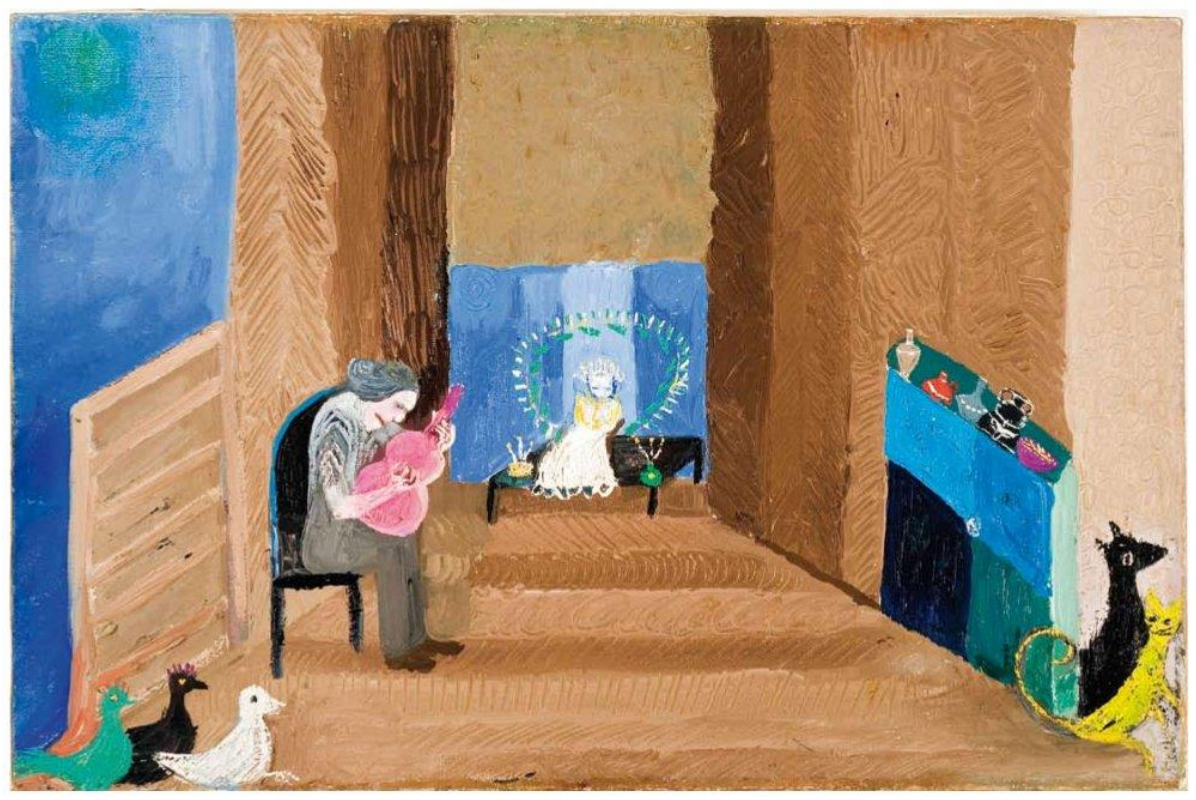


Figura 7-derecha: Violeta Parra, La guitarrera, 1963, 67 x 58 cm, óleo sobre tela, Fundación Museo Violeta Parra. Figura 7-izquierda: Violeta Parra, 1962, La Cueca, lino bordados en lanigrafía, 119.5 x $94.5 \mathrm{~cm}$ Fundación Museo Violeta Parra.
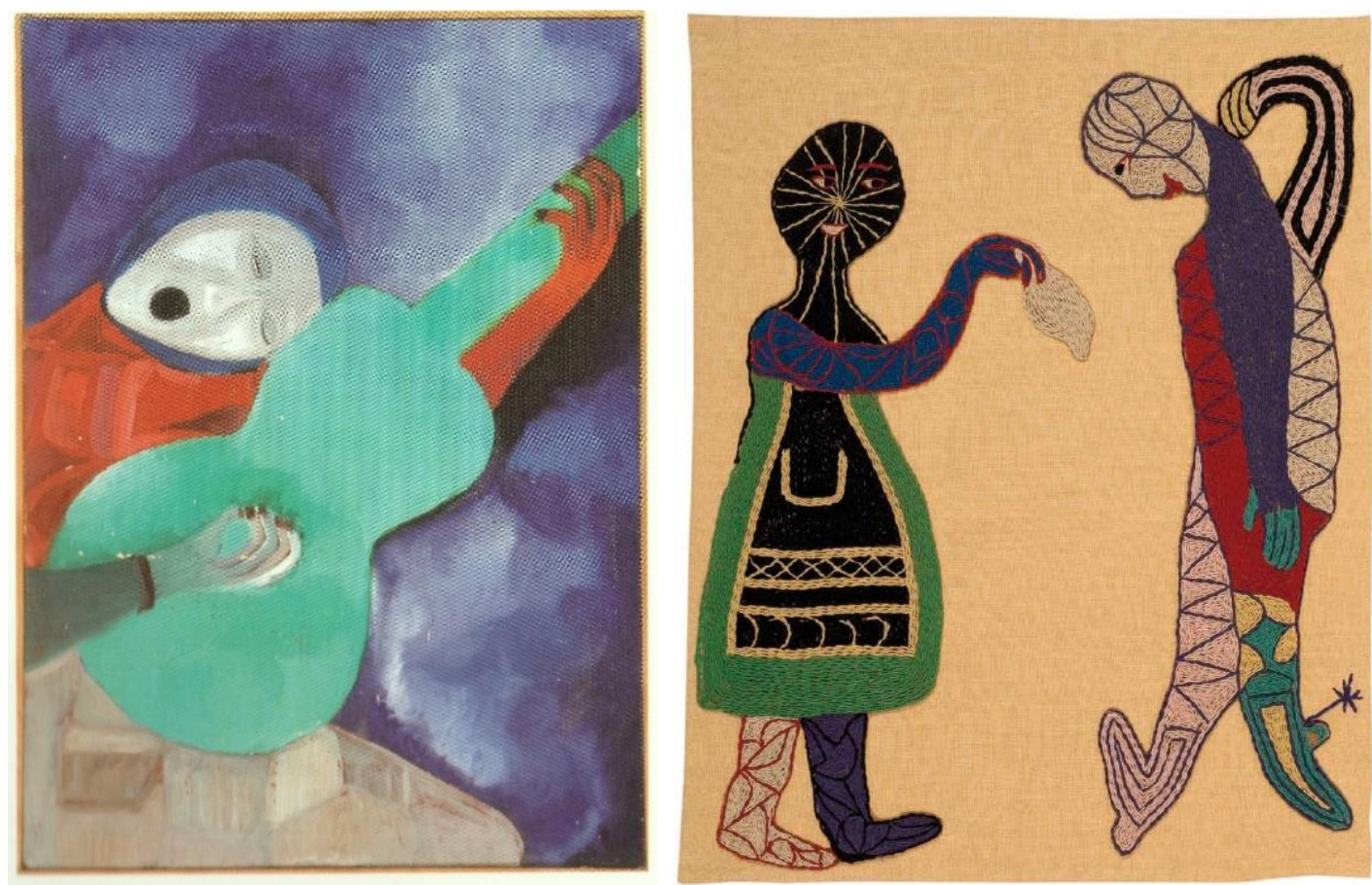

\section{Comentario Final}

En este artículo hemos podido apreciar de manera muy sintetizada algunas características de la actividad creativa de VP que muestran evidencias de las prácticas de la traducción intersemiótica, entendida aquí como la transformación o interpretación de la palabra a otro sistema semiótico. A pesar de que VP no formuló teóricamente esta práctica en un texto, podemos identificar su fundamento textual en la 'Décima III', en donde ella establece claramente el propósito intersemiótico de su poética interdisciplinaria. Se ha querido evidenciar la originalidad y habilidad de la creadora chilena para transportar poéticamente ideas, conceptos e imágenes entre diferentes sistemas semióticos. En este sentido, la investigación del canto popular de VP es reveladora y fundamental para comprender la transposición poética que realizará posteriormente. La palabra es, sin duda, el germen desde el cual la creadora nutre todo su arte, especialmente si la concebimos desde la noción aristotélica, siendo posible interpretar y proyectar la manera en que aquel lenguaje poético de VP absorbe y nutre su lenguaje musical y plástico. En términos generales, observamos en estos ejemplos que la transposición poética de VP muestra evidencias de interpretación y adaptación cuyas estructuras y contenidos son flexibles, pero expresiva y coherentemente organizadas. A pesar de que esta lectura está limitada, dado el formato de este escrito, a los ejemplos aquí expuestos, es posible proyectar igualmente este marco teórico al resto de las obras y prácticas de la propia creadora, lo que indudablemente puede matizar, transformar y enriquecer los conceptos propuestos. 


\section{Bibliografía}

Agosín, M., \& Dölz-Blackburn, I. (1992). Violeta Parra, o La expresión inefable: Un análisis crítico de su poesía, prosa, y pintura. Santiago de Chile: Planeta.

Aristotle. (1922). The poetics of Aristotle (S. H. Butcher, Ed.). London: Macmillan and Co.

Aubrey, E. (2000). The music of the troubadours. Bloomington: Indiana University Press.

Bellos, D. (2011). Is that a fish in your ear?: Translation and the meaning of everything. London: Penguin.

Benjamin, W. (2004). Selected writings (M. P. Bullock \& M. W. Jennings, Eds.). Cambridge, Mass.: Belknap Press of Harvard University Press.

Bruhn, S. (2001). A concert of paintings: "Musical ekphrasis" in the twentieth century. Poetics today, 22, 3, 551-605.

Brunhammer, Y. (1964). Violeta Parra: Musée des arts décoratifs, Louvre. [catálogo exposición] Paris: Musée des arts décoratifs, Louvre.

Dillon, L. (2013). Violeta Parra's Visual Art (PhD). King's College London, London.

Eco, U. (1979). A Theory of Semiotics. Bloomington: Indiana University Press.

Eco, U. (2004). Mouse or Rat? Translation as Negotiation. London, Phoenix.

Escobar-Mundaca, A. (2012). Violeta Parra, una aproximación a la creación interdisciplinaria (Masters). Universitat de Barcelona, Barcelona.

Escobar-Mundaca, A. (2018). I Don't Play the Guitar for Applause: Turning the World Upside Down. En Mapping Violeta Parra's Cultural Landscapes (pp. 57-71). Cham: Palgrave Macmillan.

Escobar-Mundaca, A. (2019). Translating poetics: Analysing the connections between Violeta Parra's music, poetry and art (PhD Thesis). University of Sussex.

Farias, M. (1993). Violeta Parra: A semiotic reading of a popular voice. (PhD). The Catholic University of America, Washington, D.C.

García Canclini, N. (1989). Culturas híbridas: Estrategias para entrar y salir de la modernidad. México DF: Grijalbo.

Greene, R., Cushman, S., Cavanagh, C., Ramazani, J., Rouzer, P., Feinsod, H., ... Slessarev, A. (2012). The Princeton encyclopedia of poetry and poetics. Princeton, NJ: Princeton University Press.

Jakobson, R. (1987). Language in literature (K. Pomorska \& S. Rudy, Eds.). London: Harvard University Press.

Kennedy, M., \& Bourne, J. (2004). The Concise Oxford Dictionary of Music. Oxford: Oxford University Press.

Méndez-Ramírez, H. (1999). Neruda's Ekphrastic Experience: Mural Art and Canto General. Lewisburg, Penn.: Bucknell University Press.

Miranda, P. (2001). Las décimas de Violeta Parra: Autobiografía y uso de la tradición discursiva (Masters). Universidad de Chile, Santiago de Chile.

Montealegre, J. (2011). Violeta Parra. Santiago de Chile: USACH.

Morales, L. (2003). Violeta Parra: La última canción. Santiago de Chile: Editorial Cuarto Propio.

Navasal, M. de. (1954). Conozca a Violeta Parra. ECRAN, 1220, 18-20.

Neruda, P. (1993). Canto general (J. Schmitt, Trad.). Berkeley: University of California Press.

Neruda, P. (2011). Confieso que he vivido. Madrid: Planeta.

Newton, K. M. (1997). Twentieth-century literary theory. London: Palgrave.

Oporto, L. (2013). El diablo en la música. La muerte del amor en El gavilán, de Violeta Parra. Santiago de Chile: USACH.

Parra, F. V. (2008). Violeta Parra: Obra visual (2a ed.). Santiago de Chile: Fundación Violeta Parra. 
Parra, I. (2011). El libro mayor de Violeta Parra (2a.). Santiago de Chile: Cuarto Propio.

Parra, V. (1957). Violeta Parra. El Folklore de Chile Vol. I [LP 12" / 33 1⁄3 RPM / mono] Santiago de Chile: ODEON - LDC-36019.

Parra, V. (1958). Violeta Parra. El Folklore de Chile Vol.II. [LP 12" / 33 1⁄3 RPM / mono]. Santiago de Chile: Odeón LDC-36025.

Parra, V. (1959). La Cueca Presentada Por Violeta [LP 12" / 33 1⁄3 RPM / mono]. Santiago de Chile: ODEON - LDC-36038.

Parra, V. (1965). Poésie populaire des Andes (Vol. 12). Paris: F. Maspero.

Parra, V. (1976). Décimas [LP 12" / 33 1⁄3 RPM / mono /]. Santiago de Chile: Alerce ALP-204. Parra, V. (1998). Décimas: Autobiografía en versos. Buenos Aires: Sudamericana.

Parra, V. (1999). Violeta Parra en Ginebra [2 CD / Reissue]. Santiago, Chile: Warner Music Chile.

Parra, V. (2013). Cantos folklóricos chilenos. Santiago de Chile: CEIBO.

Peirce, C. S. (1933). Collected papers of Charles Sanders Peirce. (P. Weiss \& C. Hartshorne, Eds.). Cambridge, Mass.: Harvard University Press.

Peirce, C. S. (1998). The Essential Peirce: Selected Philosophical Writings. Indiana University Press.

Pinochet, C. (2007). Violeta Parra: Hacia un imaginario del mundo subalterno (Licenciatura). Universidad de Chile, Santiago de Chile.

Ulloa, D. (1997). Neruda: Humilde traductor. Atenea (Concepción): revista de ciencias, artes y letras, 476, 85-101.

Uribe, C. (2002). Violeta Parra: En la frontera del arte musical chileno. Intramuros, 9, 8-14.

Vicuña, M. (1958). Violeta Parra, hermana mayor de los poetas populares. Revista Musical Chilena, 12, 60, 71-77. 